\title{
Study on Problems and Countermeasures of Collection Storage and Transport of Straw
}

\author{
Cai-qing $\mathrm{ZHANG}^{1, \mathrm{a}}$ and Guo-shuai $\mathrm{GAO}^{2, \mathrm{~b},{ }^{*}}$ \\ ${ }^{1}$ Department of Economics and Management, North China Electric Power University, \\ Baoding 071000, China \\ ${ }^{2}$ Department of Economics and Management, North China Electric Power University, \\ Baoding 071000, China \\ ahdzhangcaiqing@126.com, b839863960@qq.com
}

Keywords: Straw, Collection, Storage, Transport, Model.

\begin{abstract}
Straw storage is the key to the use of large-scale straw and the establishment of storage and transportation system is the basis of large-scale use of straw. In this paper, the author summarized the existing models of straw storage and transportation in China, compared the advantages and disadvantages, and put forward the existing problems and suggestions of straw storage and transportation, in order to provide reference of the efficient utilization of straw resources.
\end{abstract}

\section{Introduction}

Our country is rich in straw yield, variety and wide distribution. Straw biomass energy can be used to produce biogas and biomass power generation and bring enormous economic and social benefits. The crop cultivation of China's various regions has a big difference. Land dispersion, alternating crop planting and the characteristics of mature two times a year led to straw can only be handled by the form of scattered. A large number of straw were abandoned or incinerated also results in the low utilization of straw. Straw collection not only can effectively solve the environmental pollution but also can substitute for biomass to alleviate the air pollution. However, straw collection has the characteristics of seasonal and economical, and straw is low density and high water content, which makes straw storage and transportation a bottleneck to restrict biomass industry development. So the research of straw storage and transportation mode for improving efficiency, alleviating environmental pollution is of great significance.

At present, China scholars have carried out related investigations about the use of biomass and the collection models of straw in various regions. Xing-jun YU, Li-ming WANG investigated and analyzed the corn stalks collection and transportation technology model. According to the actual data, the economic costs, energy consumption, labor consumption and pollutant discharge of each model were calculated and analyzed[1], and concluded that it is the inevitable choice to use the seed harvesting equipment and the straw storage and transportation equipment. Xin-hua ZHU divided Shanxi Province straw collection and storage logistics system into self-use, decentralized, saving the purchasing and storage of three modes. They compared the three models and concluded that the intensive collection mode is the main development direction in the future[2]. 


\section{The Mode of Straw Collection}

Summing up the research on the straw enterprise collection model,we can divide the model of straw collection into decentralized collection and centralized collection.

\section{The Mode of Decentralized Collection}

In the decentralized mode, farmers are responsible for the collection of straw and selling straw to the straw enterprises. The main process is shown in Figure 1.

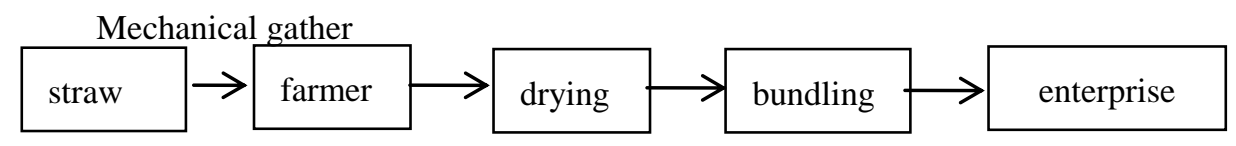

Figure 1. The mode of Decentralized collection

In this model, the majority of farmers use artificial way to collect, the few choose the mechanical methods. After bundling, they transport straw to storage or utilization enterprises via tractors and other means of transportation.

\section{Advantages and Disadvantages of the Model and its Application}

The advantages: The straw has the characteristics of loose, high moisture content, and must be dried before storage. However, it requires a large area for drying the straw. If we let the farmers to complete the drying process by themselves, there will not appears large areas of storage problems.

The disadvantages: The costs are too high to bring the poor economic performance, which make a great deal of farmers burn straw for their daily use. The implementation of the state policies on new rural construction has resulted in the space for the storage of straw in rural households a significant reduction. In addition, the farmers are not constrained makes the entire supply lack of stability, and can not guarantee the normal production needs of enterprises.

This model is suitable for the enterprises whose demand is small and relatively close to the origin of straw, such as the small straw gasification enterprises in suburb of Jiangsu Wuxi [3].

\section{The Mode of Centralized Collection}

In this mode, the middleman links the farmers with businesses. They signed a supply contract with farmers to replace the enterprises to collect straw, and transferred the qualified to the straw utilization enterprise after the pretreatment. According to the difference between brokers, the model is divided into two models: brokers-mediated and professional collection organizations. Pattern classification is as follows:

\section{Farmer-Brokers-Enterprise}

Jiangsu Zhongqian Suqian Biomass Power Plant is a typical representative of this model. It mainly takes brokers as the main part. Enterprises select competent brokers (mostly local traders with certain ability) to be responsible for the collection and transportation of straw.

In this mode, brokers mainly refer to the people engage in straw resale of the traders. They buy straw through the low price, sell it in high price. Their main advantage is to 
grasp the straw information in the case of asymmetric information.

Straw brokers often use two ways to collect, the one is the broker buy equipment and vehicles used to collect processing, acquiring straw from farmers and transporting it to the enterprise. The other is brokers do not directly purchase from farmers, but develop a number of personnel, and equip them with professional equipment. Brokers are responsible for the regular settlement with enterprises and share interests with subordinate [2]. The main process is shown in Figure 2.

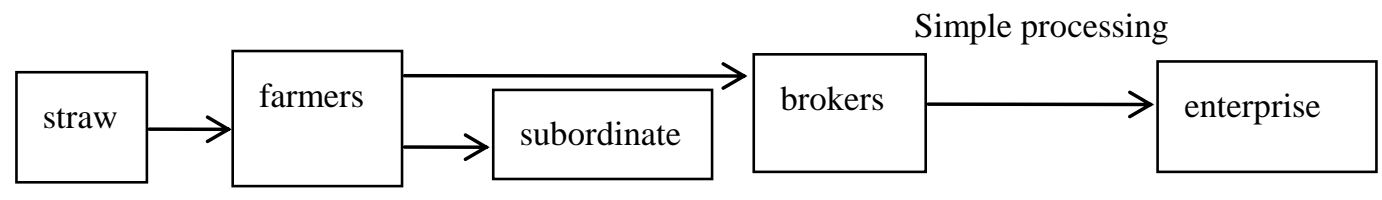

Figure 2. The mode of Farmer-Brokers-Enterprise

The advantages of this mode are as follows:

a. Brokers are responsible for the storage and transportation of straw, greatly reducing the labor of farmers.

b. Enterprises do not have to invest in the establishment of plant and purchase the related machinery and equipment, only to test the quality of straw, which reduce the operating costs in some degree[4].

The disadvantages of this mode are as follows:

a. As the state did not promulgated the relevant pricing policy, and brokes are not restricted by either farmers or businesses. In order to maximize the benefits, when brokers purchase straw they will squeeze down price, which is easy to prevent farmers to collect and sell straw, and result in a substantial reduction in straw supply.

b. The implementation of the new national energy policy makes the number of straw utilization enterprises is increasing, which lead to demand exceeds supply. When the middlemen sale the straw to the enterprise,they will raise price, resulting increase of the costs of straw acquisition and the compression of corporation profit.

This model is suitable for areas with high straw yield and few competitive industries.

\section{Farmer-Professional Collection Company-Enterprise}

The model makes the professional companies as the main body. In accordance with certain reserves standards, companies establish one or several stations in villages and towns. This model can control the size of collection and storage capacity, and supply timely to meet the needs of plant planning [5]. There is also a mode that the cooperative as the main body.[4].

In the model, the company signs the purchase contract with the enterprises, they collect straw from the farmer, carry out a series of pretreatment on the collected straw and send the qualified straw to the enterprise. The main process is shown in Figure 3.

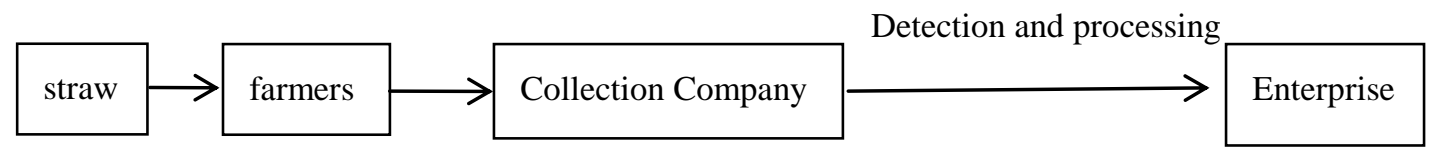

Figure 3. The mode of Farmer-Professional collection company-Enterprise

The advantages of this mode are as follows:

a. Owing to the companies are formal organizations and subjected by contract constraints, they will testing the straw, which ensure the quality of raw materials and the 
stability of long-term supply of raw[4].

b. In this model, the companies using professional machinery to carry on a series of processing. Moreover, the centralized acquisition and unified transport of straw makes the efficiency of whole process of storage and transportation greatly improved.

c. Enterprises and farmers only consider whether the price is reasonable, which bring great convenience for enterprises and farmers.

The disadvantages of this mode are as follows:

a. As a result of the demand of a large area and the need of human and material resources for routine maintenance and management, which lead to an increase in the cost. The collection companies have to face the risk of loss of contract and breach of contract affected by the weather such as rain and snow [2].

b. Only a small number of villages are willing to invest in the establishment of cooperatives, and this model also increased the length of the supply chain, reducing the profits of the main body [4].

c. This model requires a high level management, and a certain amount of investment in the initial stage. The input-output ratio influences the positivity to participate in the construction of the straw collection and storage system [6].

This model is suitable for areas with high straw yield and a large number of straw utilization enterprises, such as Yangzhou Gaoyou [6].

\section{Farmer-Internal Collection Department of Enterprise}

This model links the straw utilization enterprises with farmers directly. Enterprises invest to establish the straw purchasing and storage center and arrange special personnel in charge of straw acquisition and the follow-up storage transportation and other tasks. The straw collection departments will set up the corresponding storage points in accordance with the number of regional straw production. The main process is shown in Figure 4.

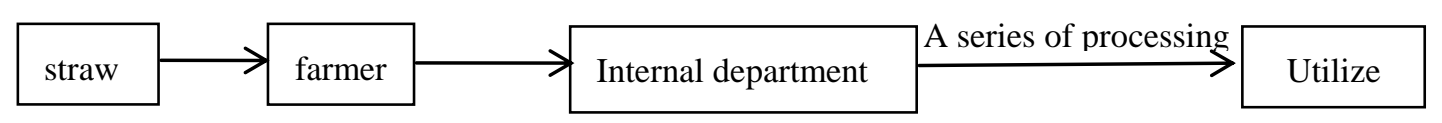

Figure 4. The mode of Farmer-Internal Collection Department of Enterprise

The advantages of this mode are as follows:

a. Enterprises collect straw on their own reduce the risk of brokers raising prices and avoid competition with other raw materials enterprises.

b. Companies can participate in the management and control of the entire straw storage and transportation process, which can reducing costs and improve efficiency.

c. Self-built purchasing and storage center need to set up relevant logistics department, if properly managed, they may develop into a third-party logistics company. Enterprises can take the initiative in the collection of raw materials and obtain additional revenue, and affect other companies to help to form a monopoly [4].

The disadvantages of this mode are as follows:

The establishment of purchasing and storage center, straw collection process involved in the personnel arrangements need to invest a lot of money. The business operators also need the excellent management talents in case of the operational difficulties.

The model is suitable for large-scale and well-funded large-scale power plants [6]. 


\section{Problems in Straw Collection, Storage and Transportation}

Through the above analysis, we can find out the following problems in the process of straw collection through the analysis of straw storage and transportation mode.

\section{Low Collecting Will}

China's urbanization level gradually increased and a large number of rural labor force transfer to the town. Most of young people choose to go out to work, the rural population was aging trend and their environmental awareness is poor. Compared with the income from the work, the cost and time needed to collect the straw and transport it to the purchasing and storage point are not satisfied which lead to the farmers' enthusiasm to sell straw is low and straw are discarded or incinerated. .

\section{Low Mechanization of the Collection Process}

The presence of straw-handling equipment, such as bundlers, facilitates farmers' participation in the crop straw market [8]. However, due to the lack of efficient collection, bundling equipment makes waste in the collection process is serious; resulting in straw cannot achieve large-scale comprehensive utilization. In addition, large energy consumption and carbon dioxide emissions during storage result in the cost of labor costs and fuel consumption accounts takes a great proportion [1].

\section{Lack of the Perfect Straw Supply System}

The straw supply model in abroad such as IBSAL, SHAM can directly guide the whole process of collection, storage and transportation and reduce the straw supply cost[10]. Although the way of direct combustion power generation improves the utilization rate of straw, they have the problem of instability in the supply and high costs. From the way of collection to the set of price, it's lack of the professional theoretical model. In addition, due to straw brokers without constraints and formal training, which is difficult to ensure a stable supply of straw.

\section{There is no Unfied Price of Straw}

The economic benefits brought by biomass energy are recognized by the public and the national policy makes amounts of straw utilization enterprises established. China's straw are variety, but with the development of the paper industry, the straw market facing resource competition. As brokers and professional companies will pursue maximize interests, the most direct approach is to increase the price of straw or to reduce the quality of straw. In order to seek the lowest cost, the enterprises will expand the acquisition radius, resulting in disorderly rise in operating costs[7]. These are making the stability of straw supply is facing a severe test.

\section{Countermeasures and Suggestions}

There are some recommendations in view of the straw collection and transportation process of the existing problems.

(1) Accelerate scientific research and development efforts: Reasonable use of machinery and reduction of labor consumption is one of the effective ways to reduce the total cost of wheat stalks [10]. In order to achieve the large-scale use of straw, we must 
pay attention to the technology research at first and learn foreign advanced technology and models for developing of machinery and equipment to achieve the mechanization of straw collection, which will improve the efficiency of straw collection, reduce the cost and gradually realize the commercialization of straw.

(2) Construct a reasonable profit distribution and pricing mechanism: In the market economy-based system, the pursuit to the maximize interests will lead to the parties to the uneven distribution of profits. China's straw industry development mainly relies on the support from government financial subsidies. Therefore, the government should coordinate the interest's distribution of the three parties, introduce the relevant pricing policy to control the high price behavior, which is conducive to the stability of the straw supply system and development.

(3) Increase publicity and financial subsidies: In order to solve the problem of low willingness of collecting straw, the Government can carry out technology training or activities about straw collection, which will make they truly recognize the benefits of straw collection and reduce the burning behavior. Straw-rich rural areas can be invested by the local government a certain number of processing equipment to reduce cost. In addition, increase the relevant subsidies of the purchase of equipment and exempt purchase tax are beneficial to the circulation of straw.

(4) Pay attention to the research of straw supply system: Improve the current straw supply system is the key factors to achieve large-scale use of straw and industrial management. The current priority is to establish an efficient, low-cost collection transportation system that is suitable to the actual situation. Therefore, the state should speed up the construction of straw logistics facilities in rural areas and establish relevant research departments to develop straw-specific logistics management information system so that parties can keep abreast of relevant information [11].

(5) Use clean energy to supply electric: Studies have shown that a certain degree of compression treatment in the collection of straw is conducive to reduce the long-distance collection costs [12]. Although the straw after the compression treatment greatly reduces the pollutant emissions, the consumption of oil and electricity in the transportation process will pollute the environment. Therefore, the energy consumed by the machinery during the procession can be provided by clean energy sources such as wind power or solar energy.

\section{Acknowledgement}

This research was financially supported by Science and technology project of Hebei Province "Research on the innovation of rural biomass energy development in Beijing, Tianjin and Hebei Province based on industrial chain collaborative planning" (No: 16454317D).

\section{References}

[1] Xing-Jun YU, Li-Ming WANG, Feng-De WANG and Jun-Hua XIAO, Journal of Agricultural Mechanization Research. 05 (2013) 24-28. (In Chinese)

[2] Xin-Hua ZHU, Zhong-Ping YANG, Journal of Agricultural Mechanization Research. 07 (2011) 60-72. (In Chinese)

[3] Ju LIU, Ding-Cai ZHOU, China Resources Comprehensive Utilization. 31 (2013) 44-47. (In Chinese) 
[4] Xiao-Jie JIN, Wei QU, Jing-Wen CHEN, Xiang GAO, Journal of Anhui Agricultural Sciences. 08 (2014) 2487-2489. (In Chinese)

[5] Zai-Tao SHI, Study on Fuel Supply of Henan Straw Power Generation, Henan Agricultural University. (2011). (In Chinese)

[6] Ying-Hua PING, Chinese Agricul Tural Mechanization. 05 (2014) 326-330.(In Chinese)

[7] Yan-Li ZHANG, Fei WANG, Li-Xin ZHAO, Li-Ying SUN, Renewable Energy. 01 (2009) 1-5. (In Chinese)

[8] Xue-Lian WU, Jun-Biao ZHANG, Jun-Hui FENG, Journal of Arid Land Resources and Environment. 02 (2017) 79-84. (In Chinese)

[9] Juan-Juan WU, Li-Li HUO, Li-Xin ZHAO, Zong-Lu YAO, Hai-Bo MENG Journal of Agricultural Mechanization Research. 03 (2016) 263-268. (In Chinese)

[10] Yan-Ru FANG, Shu-Hua LIU, Lin-Feng WANG, Lan-Tian REN, Journal of China Agricultural University. 02 (2014) 28-35. (In Chinese)

[11]Xue WANG, Zhi-Zhou CHANG, Xiao-Hua WANG, Agro-Environment and Development. 01 (2016) 10-16. (In Chinese)

[12] Ai-Hua XING, Gang LIU, Yao WANG, Fei WEI and Yong JIN, Chinese Journal of Process Engineering. 02 (2008) 305-313. (In Chinese) 